\title{
Developmental control of the DNA replication and transcription programs
}

\author{
Jared Nordman, ${ }^{1}$ Sharon $\mathrm{Li}^{1}{ }^{1}$ Thomas Eng, $^{1}$ David MacAlpine, ${ }^{2}$ \\ and Terry L. Orr-Weaver ${ }^{1,3}$ \\ ${ }^{1}$ Whitehead Institute and Department of Biology, Massachusetts Institute of Technology, Cambridge, Massachusetts 02142, USA; \\ ${ }^{2}$ Department of Pharmacology and Cancer Biology, Duke University Medical Center, Durham, North Carolina 27710, USA
}

\begin{abstract}
Polyploid or polytene cells, which have more than 2C DNA content, are widespread throughout nature and present in most differentiated Drosophila tissues. These cells also can display differential replication, that is, genomic regions of increased or decreased DNA copy number relative to overall genomic ploidy. How frequently differential replication is used as a developmental strategy remains unclear. Here, we use genome-wide array-based comparative genomic hybridization $(\mathrm{aCGH})$ to profile differential DNA replication in isolated and purified larval fat body and midgut tissues of Drosophila, and we compare them with recent aCGH profiles of the larval salivary gland. We identify sites of euchromatic underreplication that are common to all three tissues and others that are tissue specific. We demonstrate that both common and tissuespecific underreplicated sites are dependent on the Suppressor of Underreplication protein, SUUR. mRNA-seq profiling shows that whereas underreplicated regions are generally transcriptionally silent in the larval midgut and salivary gland, transcriptional silencing and underreplication have been uncoupled in the larval fat body. In addition to revealing the prevalence of differential replication, our results show that transcriptional silencing and underreplication can be mechanistically uncoupled.
\end{abstract}

[Supplemental material is available for this article. The sequence data from this study have been submitted to the NCBI Gene Expression Omnibus (http://www.ncbi.nIm.nih.gov/geo) under accession no. GSE25025.]

Polyploid or polytene tissues are common throughout development in plants and animals. Both have increased DNA copy number, but they differ in their arrangement of replicated chromatids, with sisters being aligned in polytene chromosomes (Edgar and OrrWeaver 2001; Lilly and Duronio 2005). In mammals, for example, polyteny occurs in trophoblasts, and megakaryocytes are polyploid (Zimmet and Ravid 2000). Nearly all differentiated cell types in Drosophila are polytene. Polyteny arises by repeated $\mathrm{G} \rightarrow \mathrm{S}$ cycles, termed the endo cycle, rather than continuous replication or a prolonged $\mathrm{S}$ phase. This provides a mechanism to generate large, highly metabolically active cells (Edgar and Orr-Weaver 2001; Lilly and Duronio 2005; Lee et al. 2009).

In polytene cells, increases in gene copy number are not necessarily uniform throughout the genome (Edgar and Orr-Weaver 2001). This differential replication can generate regions of amplification or regions of decreased copy number relative to overall genomic ploidy, termed underreplication. Gene amplification occurs in Drosophila ovarian follicle cells, in which developmentally regulated, repeated rounds of origin firing produce gradients of DNA copy number with peaks at defined origins of replication and decreasing flanking copy number (Claycomb et al. 2004). Conversely, heterochromatic sequences of the Drosophila genome are underreplicated in most polytene tissues, and this underreplication is dependent on the suppressor of underreplication protein, SUUR (Belyaeva et al. 1998). Constrictions termed intercalary heterochromatin have been observed cytologically in the giant chromosomes of the larval salivary gland, and these also are SUUR

\footnotetext{
${ }^{3}$ Corresponding author.

E-mail weaver@wi.mit.edu.

Article published online before print. Article, supplemental material, and publication date are at http://www.genome.org/cgi/doi/10.1101/gr.114611.110. Freely available online through the Genome Research Open Access option.
}

dependent (Belyaeva et al. 1998). Whether underreplication is common in euchromatic regions across different tissue types and how commonly gene amplification occurs remain unclear.

Genomics provide the means to determine how often differential replication is used as a developmental strategy. Array-based comparative genomic hybridization (aCGH) allows for the rapid identification of DNA copy number differences on a genome-wide scale, but it is imperative that this be done on dissected, isolated tissues. aCGH permits one to build on inferences from cytology by identifying, at a molecular and sequence level, differentially replicated regions in polytene chromosomes. Due to their repetitive nature, however, heterochromatic sequences cannot be accurately assessed by aCGH-based methods. We have used aCGH to profile genome-wide differential replication in the larval salivary gland and found underreplication of euchromatic sequences (N Sher, S Li, G Bell, T Eng, M Eaton, D MacAlpine, and TL Orr-Weaver, in prep.).

Polytene chromosomes have been cytologically analyzed in larval fat body and midgut tissues, which both have fascinating physiologies (Hochstrasser 1987; Marchetti et al. 2003). The larval fat body is a highly metabolically active, nutrient sensor that performs functions analogous to the vertebrate liver (Leopold and Perrimon 2007). The larval fat body disperses into individual cells during metamorphosis (Butterworth and Forrest 1984). How the remodeling of the larval fat body is able to generate the adult fat body remains poorly understood. In contrast, the larval midgut is responsible for nutrient uptake and is composed of large polytene cells and diploid imaginal cells (Skaer 1993). The two cell types of the larval midgut respond to the steroid hormone ecdysone in different ways during metamorphosis, as the diploid cells produce the adult midgut but the larval midgut is histolyzed (Li and White 2003; Jiang et al. 2009; Mathur et al. 2010). Polytene structures of both larval midgut and fat body chromosomes show banding patterns similar to those of the larval salivary gland (Hochstrasser 
1987). For example, a constriction has been observed at the bithorax locus at 89D-89E on larval fat body chromosomes, and this was further demonstrated to be associated with underreplication at that locus, as in the salivary gland (Marchetti et al. 2003). To quantitatively measure genome-wide differential replication, however, genomic techniques such as aCGH are necessary.

Here, we perform aCGH to profile genome-wide differential replication in the larval fat body and midgut tissues, and we compare them with recent aCGH profiles of the larval salivary gland from the modENCODE project to generate a three-tissue comparative analysis of differential replication. Furthermore, we transcriptionally profiled these tissues to determine the relationship between transcription and differential replication on a genome-wide scale. Our results demonstrate a developmental plasticity of both underreplication and transcription of genes within these regions.

\section{Results}

\section{Underreplication in polytene tissues}

Given that most differentiated tissues in Drosophila are polytene, it is of interest to compare patterns of genomic replication across these tissues to determine whether there are changes in gene copy number of specific intervals relative to overall ploidy. We recently found that in the salivary gland, nonrepetitive, gene-encoding regions are underreplicated (N Sher, S Li, G Bell, T Eng, M Eaton, D MacAlpine, and TL Orr-Weaver, in prep.). Therefore, we wanted to determine whether this is also true in other polytene tissues and, if so, whether underreplicated regions are conserved or distinct.

To profile larval fat body and midgut it was necessary to first isolate pure tissues. To this end, both tissue types were isolated from wandering third instar larvae by dissection, and genomic DNA was extracted from the dissected material. DNA was Cylabeled for comparative genomic hybridization (aCGH). The tissue genomic DNA and control Cy-labeled embryonic DNA were hybridized to Agilent whole-genome tiling arrays that contained a $\sim 60$-mer probe on average every 125 or $250 \mathrm{bp}$. We used larval salivary gland aCGH data (N Sher, S Li, G Bell, T Eng, M Eaton, D MacAlpine, and TL Orr-Weaver, in prep.) as a reference set of underreplicated regions to generate a three-tissue comparison.

We focused on differential gene copy number within euchromatic regions of the genome, given that heterochromatic regions are known to be underreplicated and also were not present on our arrays (Spradling and Orr-Weaver 1987). In both larval fat body and midgut we observed underreplication of nonrepetitive, gene-encoding regions shown to be distinct from heterochromatin (Filion et al. 2010). Underreplication was defined by a twofold reduction in copy number in regions of $10 \mathrm{~kb}$ or greater in two independent aCGH experiments (Fig. 1A; Supplemental Fig. S1). No regions were amplified in copy number above the overall genomic ploidy level. To confirm that the aCGH profiles accurately reflect copy number changes within underreplicated regions, we performed quantitative real-time PCR (qPCR) on five genomic loci that displayed varying degrees of underreplication across both tissues (Fig. 1B). Our results indicate that aCGH accurately reflects copy-number changes seen in underreplicated regions. These regions contain single-copy genes and lack highly repetitive satellite sequences and, moreover, they do not have a larger number of transposable element insertions compared with flanking, fully replicated intervals.

We observed a total of 40 underreplicated euchromatic sites present in the fat body, midgut, or salivary gland tissues. Of these 40 sites, 19 were present in the fat body or midgut, and eight were present in all three tissue types (Table 1). It was striking that the characteristics of underreplication varied between the three tissues, with the larval fat body showing the least number of underreplicated euchromatic regions and the smallest reduction in copy number within those regions (Table 1; Fig. 1; Supplemental Fig. S1).

In addition to sites of underreplication common among tissue types, we observed tissue-specific cases of underreplication (Table 1; Fig. 1A; Supplemental Fig. S1). Of the 19 euchromatic underreplicated regions present in either fat body or midgut tissues, two regions were midgut specific $(21 \mathrm{~F}-22 \mathrm{~A}, 32 \mathrm{E}-32 \mathrm{~F})$, and two were fat body specific $(24 \mathrm{D}, 36 \mathrm{E}-36 \mathrm{~F})$ (Table 1$)$. We also found regions of underreplication common to two tissue types, but lacking in the third. For example, we observed underreplicated regions present in fat body and midgut tissues, but not in the salivary gland (e.g., 7B) (Table 1). Multiple regions, such as $25 \mathrm{~A}$ and 35B, are present in the salivary gland and midgut, but absent in the fat body. Likewise, the underreplicated region at $64 \mathrm{C}$ is present in salivary gland and

\section{Genome Research www.genome.org}


Table 1. Chromosomal and cytological locations of underreplicated regions

\begin{tabular}{|c|c|c|c|c|c|c|c|}
\hline Chromosome & Start & End & $\begin{array}{l}\text { Cytological } \\
\text { position }\end{array}$ & Midgut & $\begin{array}{c}\text { Fat } \\
\text { body }\end{array}$ & $\begin{array}{l}\text { Salivary } \\
\text { gland }\end{array}$ & Size (bp) \\
\hline \multicolumn{8}{|l|}{ Class I } \\
\hline $\operatorname{chr} X$ & $11,946,162$ & $12,302,525$ & $11 \mathrm{~A}$ & + & + & + & 356,363 \\
\hline $\operatorname{chr} X$ & $14,180,437$ & $14,480,743$ & $12 \mathrm{E}-12 \mathrm{~F}$ & + & + & + & 300,306 \\
\hline $\operatorname{chr} X$ & $20,452,823$ & $20,899,277$ & 19D-19E & + & + & + & 446,454 \\
\hline $\operatorname{chr} 2 L$ & $15,941,876$ & $16,226,438$ & $35 \mathrm{E}-35 \mathrm{~F}$ & + & + & + & 284,562 \\
\hline $\operatorname{chr} 2 L$ & $16,923,976$ & $17,352,361$ & $36 \mathrm{~B}-36 \mathrm{C}$ & + & + & + & 428,385 \\
\hline $\operatorname{chr} 2 R$ & $18,999,371$ & $19,233,495$ & $59 C-59 D$ & + & + & + & 234,124 \\
\hline $\operatorname{chr} 3 L$ & $13,532,683$ & $13,859,200$ & $70 B-70 C$ & + & + & + & 326,517 \\
\hline $\operatorname{chr} 3 L$ & $18,174,956$ & $18,565,023$ & $75 C-75 D$ & + & + & + & 390,067 \\
\hline \multicolumn{8}{|l|}{ Class II } \\
\hline $\operatorname{chr} X$ & $7,273,404$ & $7,513,649$ & 7B & + & + & - & 240,245 \\
\hline \multicolumn{8}{|l|}{ Class III } \\
\hline $\operatorname{chr} X$ & $2,840,892$ & $3,047,102$ & $3 C$ & + & - & + & 206,210 \\
\hline $\operatorname{chr} 2 L$ & $4,543,536$ & $4,7674,88$ & $25 \mathrm{~A}$ & + & - & + & 223,952 \\
\hline $\operatorname{chr} 2 L$ & $14,738,470$ & $14,977,831$ & $35 B$ & + & - & + & 239,361 \\
\hline $\operatorname{chr} 2 L$ & $17,528,029$ & $17,961,550$ & $36 C-36 D$ & + & - & + & 433,521 \\
\hline $\operatorname{chr} 3 R$ & $12,482,529$ & $12,793,969$ & 89D-89E & + & - & + & 311,440 \\
\hline \multicolumn{8}{|l|}{ Class IV } \\
\hline $\operatorname{chr} 2 L$ & $1,266,661$ & $1,488,558$ & $21 \mathrm{~F}-22 \mathrm{~A}$ & + & - & - & 221,897 \\
\hline $\operatorname{chr} 2 L$ & $11,310,367$ & $11,482,954$ & $32 \mathrm{E}-32 \mathrm{~F}$ & + & - & - & 172,587 \\
\hline \multicolumn{8}{|l|}{ Class V } \\
\hline $\operatorname{chr} 3 L$ & $4,832,869$ & $5,102,410$ & $64 C$ & - & + & + & 269,541 \\
\hline \multicolumn{8}{|l|}{ Class VI } \\
\hline $\operatorname{chr} 2 L$ & $3,932,045$ & $4,195,034$ & $24 \mathrm{D}$ & - & + & - & 262,989 \\
\hline $\operatorname{chr} 2 L$ & $18,189,391$ & $18,388,687$ & $36 \mathrm{E}-36 \mathrm{~F}$ & - & + & - & 199,296 \\
\hline \multicolumn{8}{|c|}{ Class VII: Underreplicated regions within arm heterochromatin } \\
\hline $\operatorname{chr} X$ & $21,976,372$ & $22,320,723$ & $20 \mathrm{D}-20 \mathrm{~F}$ & + & - & - & 344,351 \\
\hline $\operatorname{chr} 3 L$ & $23,361,303$ & $23,661,523$ & $80 \mathrm{~F}$ & + & + & + & 300,220 \\
\hline $\operatorname{chr} 3 L$ & $23,755,753$ & $24,012,145$ & $80 \mathrm{~F}$ & + & + & + & 256,392 \\
\hline $\operatorname{chr} 3 L$ & $24,054,878$ & $24,430,701$ & $\mathrm{NA}(>80 \mathrm{~F})$ & + & + & + & 375,823 \\
\hline $\operatorname{chr} 3 R$ & $23,818,957$ & $24,117,940$ & $98 B-98 C$ & + & - & + & 298,983 \\
\hline
\end{tabular}

(-) Fully replicated; (+) underreplicated.

fat body, but absent in the midgut (Table 1; Fig. 1A; Supplemental Fig. S1). Because underreplication is tissue specific, differentiation must result in changes in the endo cycle and/or chromatin structure that alter the sites that are differentially replicated.

One possibility was that the number of underreplicated sites and the fold-underreplication would correlate with the degree of ploidy in the three tissue types. For example, if a site was underreplicated in each endo cyle, then a copy number decrease proportional to the number of endo cycles would be expected at that site. To determine ploidy we measured the intensity of DAPI staining in dissected tissues relative to diploid control cells (Supplemental Fig. S3). We calculated the average ploidy values of fat body, midgut, and salivary gland cells to be $225 \mathrm{C} \pm 9,171 \mathrm{C} \pm 19$, and $1669 \mathrm{C} \pm 104$, respectively (mean \pm SEM). This is consistent with previous analysis on these tissues, including the presence of two types of polyploid cells in the larval midgut (Rodman 1967; Butterworth and Rasch 1986; Hochstrasser and Sedat 1987). The diploid cells from the imaginal islands in the midgut were clearly distinguishable by nuclear size and not quantified. The quantification of ploidy in the salivary gland suggests that there are two populations of cells that differ by one having undergone an additional endo cycle. Given that cells in the salivary gland are not synchronously undergoing DNA replication during the larval stages, some cells are in S phase, while others are in $\mathrm{G}$ phase (Rodman 1967; Smith and Orr-Weaver 1991). This results in two populations of cells that differ by a single endo cycle, which we observed (Supplemental Fig. S3).

The number of underreplicated sites and fold underreplication are correlated with ploidy levels when comparing salivary gland and midgut tissues (Table 1; Fig. 1B; Supplemental Fig. S1). In contrast, the fat body tissue differs in that the number of underreplicated sites and fold underreplication are less than that of midgut, although both tissues have a similar ploidy level (Table 1; Supplemental Figs. S3, S4). Therefore, there is no direct correlation between the number of underreplicated sites, fold underreplication, and ploidy in the fat body tissue.

\section{The SUUR protein affects replication in larval fat body and midgut tissues}

The SUUR protein is necessary for underreplication in the salivary gland, and in its absence the vast majority of underreplicated regions become fully replicated (Belyaeva et al. 1998; N Sher, S Li, G Bell, T Eng, M Eaton, D MacAlpine, and TL Orr-Weaver, in prep.). Given that the function of the SUUR protein in promoting underreplication has only been described in the salivary gland, we wanted to test whether SUUR performs a similar function in other tissues that display regions of underreplication. We used aCGH to profile copy-number variation in midgut and fat body tissues derived from the SuUR mutant. Strikingly, SUUR affects all underreplicated regions in both the midgut and fat body tissues, with all of the underreplicated regions becoming fully replicated (Fig. 2; Supplemental Figs. S2, S4). Therefore, SUUR has a general function to control replication levels in a variety of tissues. Given the tissue-specific differences in underreplication, however, SUUR cannot be the sole factor responsible for determining the sites of underreplication.

\section{Transcriptional profiling of larval fat body and midgut tissues}

In addition to promoting underreplication, genomic regions associated with SUUR have been shown to be transcriptionally silent (Pindyurin et al. 2007). Furthermore, a recent genome-wide survey of 53 chromatin proteins in Drosophila cell culture has identified a unique repressive chromatin state associated with SUUR (Filion et al. 2010). In addition to SUUR, this chromatin domain termed "BLACK" chromatin is associated with several other proteins such as histone $\mathrm{H} 1$ and lamin, and lamin was previously shown to be correlated with SUUR binding (Pindyurin et al. 2007). BLACK chromatin appears to be a major type of repressive chromatin distinct from heterochromatin that is late replicating, has a low density of ORC binding, and is largely transcriptionally inactive. The SUUR-dependent underreplicated regions we identified in larval midgut and fat body provided the opportunity to test whether underreplication and gene expression are developmentally linked across multiple tissue types within this repressive chromatin domain. Previous results have demonstrated that in the underreplicated domains of the salivary gland transcription is blocked (N Sher, S Li, G Bell, T Eng, M Eaton, D MacAlpine, and TL Orr-Weaver, in prep.). 


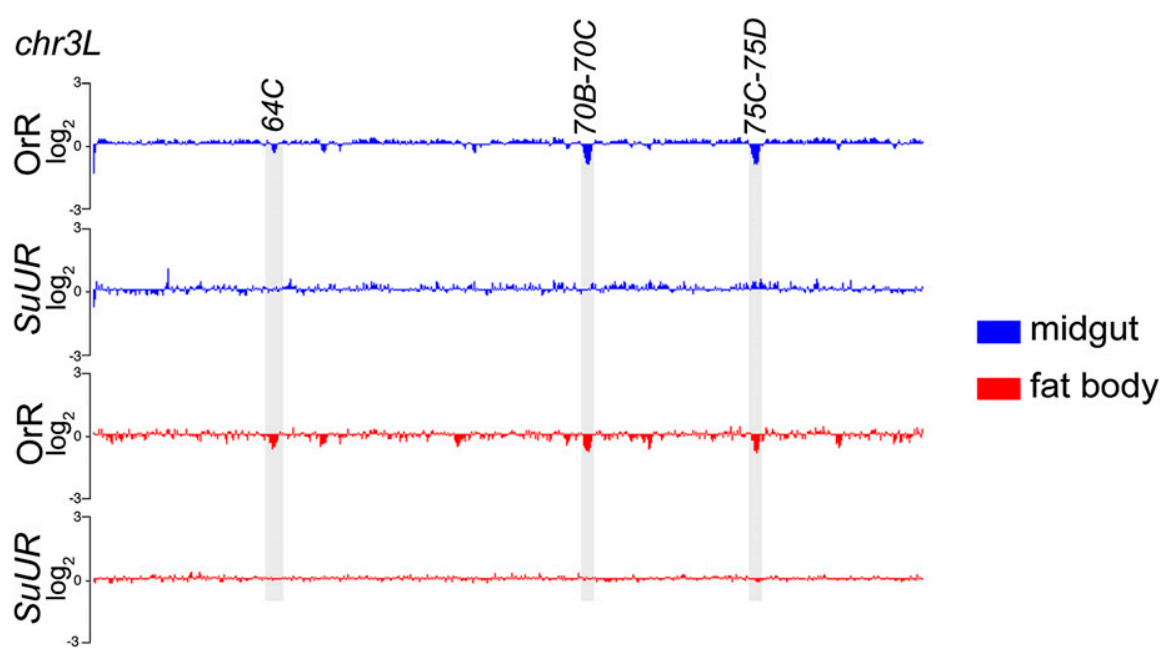

Figure 2. The SUUR protein affects underreplication in larval midgut and fat body tissues. aCGH profiles of the left arm of chromosome $3 L$ (chr3L:1-22,955,576) comparing OregonR and SuUR mutant tissues. Sites of underreplication (highlighted) are lost in the SUUR mutant.

To quantify the level of gene expression in larval fat body and midgut tissues, mRNA-seq was performed on cDNA generated from RNA isolated from these dissected tissues. We obtained 18.5 and 12.8 million unique reads for fat body and midgut tissues, respectively. Additionally, we used mRNA-seq data from salivary gland tissue as a reference to create a threetissue comparison (N Sher, S Li, G Bell, T Eng, M Eaton, D MacAlpine, and TL Orr-Weaver, in prep.). This enabled us to analyze gene expression in regions that are underreplicated in all three tissue types (common underreplicated regions), regions of underreplication specific to a particular tissue, or regions underreplicated in two tissues but present at full copy number in the third (Table 1; Fig. 1; Supplemental Fig. S1).

In the larval midgut, the vast majority of transcripts in common underreplicated regions are not expressed (137/ $151)$, as observed in the salivary gland (Figs. 3, 4; Supplemental Table 2; N Sher, S Li, G Bell, T Eng, M Eaton, D MacAlpine, and TL Orr-Weaver, in prep.). Similarly, in the three midgut-specific underreplicated regions, only $3.8 \%(1 / 26)$ of transcripts were expressed. We also observed that the transcripts expressed within the common underreplicated regions in the midgut were all located at the edges of their corresponding underreplicated region. Therefore, underreplicated domains in the midgut and salivary gland tissues behave similarly to the repressed chromatin domain associated with SUUR binding in tissue culture (Pindyurin et al. 2007; Filion et al. 2010).

The larval fat body markedly contrasts with the larval midgut and salivary gland, in that many transcripts within Table 1. underreplicated regions are expressed (Figs. 3, 4; Supplemental Table 2). Approximately $36 \%(54 / 151)$ of transcripts in common underreplicated regions are expressed in the fat body, and the genes expressed in these regions are distributed throughout the sides and bottoms of the troughs. Generally, within one underreplicated region some transcripts are on and some are off. This trend also was observed in fat body-specific underreplicated regions where $\sim 31 \%(8 / 26)$ of transcripts were expressed. Furthermore, 33\% $(67 / 206)$ of transcripts within all of the underreplicated regions of the fat body were expressed, which contrasts with the underreplicated regions of the midgut and salivary glands, 7\%(19/262), 7\%(32/ 478), respectively (Fig. 4). These results indicate that SUUR-dependent promotion of underreplication is not sufficient to prevent transcription. Furthermore, the fact that transcription occurs in regions of underreplication in the fat body indicates that transcriptional shut off is not necessary for underreplication to occur.

How might underreplication and the absence of transcription be linked? It has been shown that ORC binding and origin
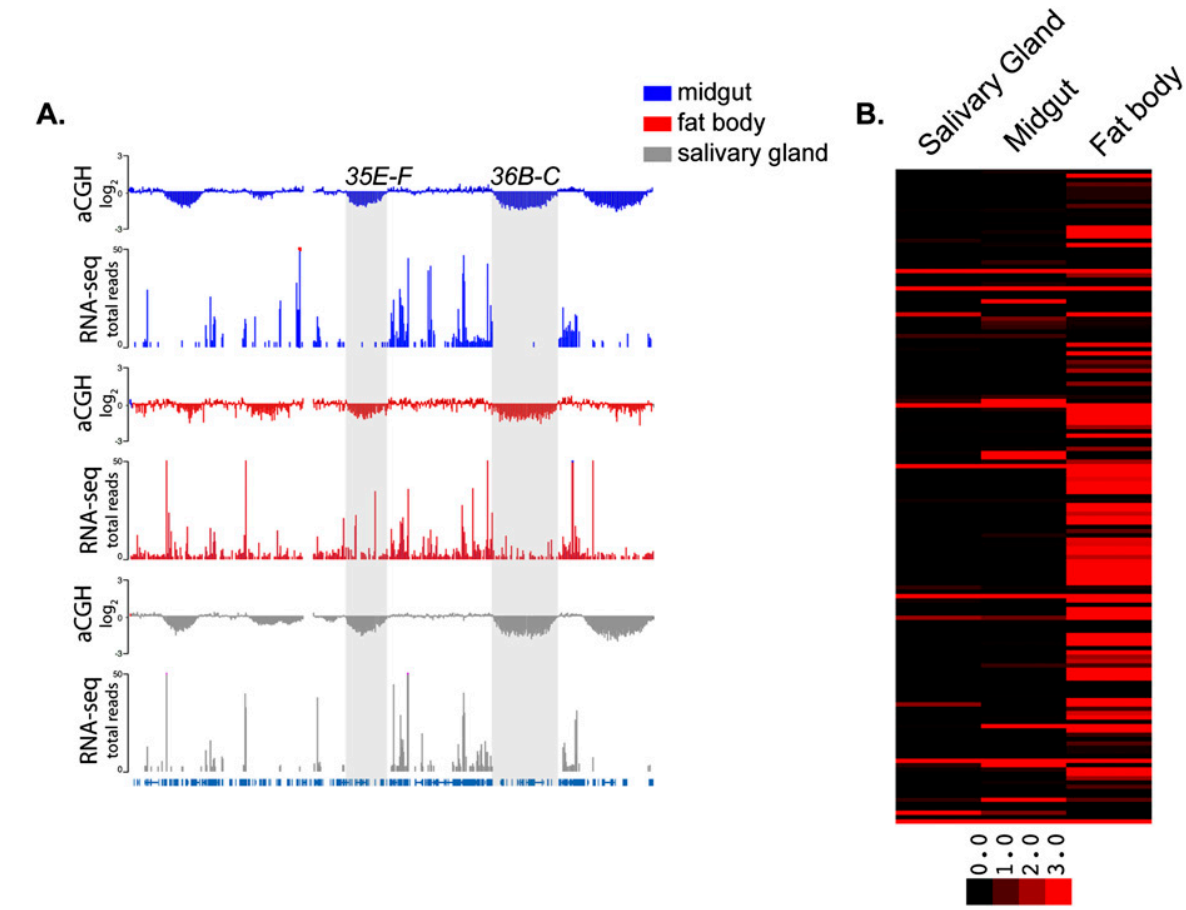

Figure 3. Tissue-specific differences in transcription across common underreplicated genomic loci. (A) aCGH profiles of copy number differences and RNA-seq showing the level of transcription within those regions. Sites of common underreplication are highlighted. RNA-seq data for the salivary gland was obtained from modENCODE (N Sher, S Li, G Bell, T Eng, M Eaton, D MacAlpine, and TL Orr-Weaver, in prep.) (chr2L:14,500,000-18,000,000). (B) A heat map of the 151 transcripts within the 11 common regions of underreplication shows that many transcripts are expressed in larval fat body relative to larval salivary gland or larval midgut tissues (generated with Cluster/TreeView) (Eisen et al. 1998). Each row represents a transcript and each column represents a tissue type. Only RPKM values of $\geq 3$, represented as dark red, are considered expressed. The raw data used in the heat map can be found in Supplemental

\section{Genome Research} www.genome.org 


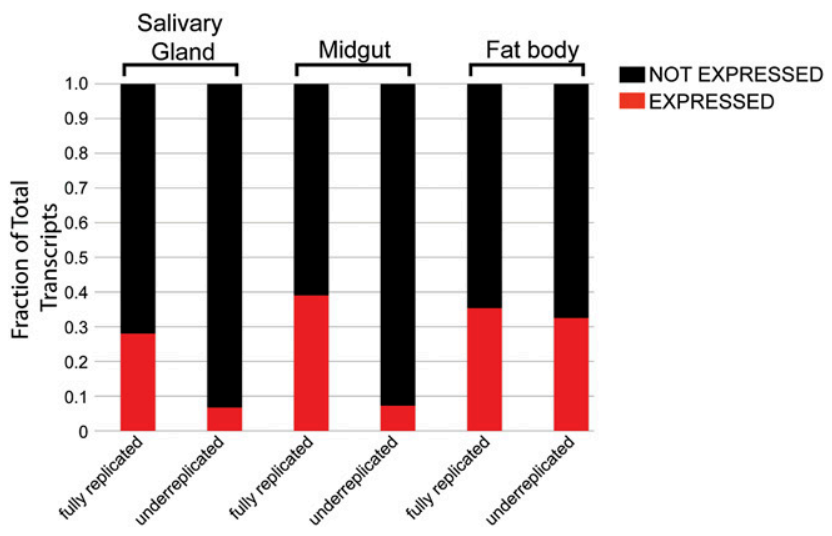

Figure 4. Fat body-specific increases in gene expression within underreplicated regions relative to fully replicated regions. The fraction of transcripts expressed $(\mathrm{RPKM} \geq 3.0)$ or not expressed (RPKM $<3.0)$ in each tissue type in either the underreplicated or fully replicated regions of each tissue.

activation are correlated with active transcription (Hatton et al. 1988; Schubeler et al. 2002; MacAlpine et al. 2004; Jeon et al. 2005). Therefore, lack of transcription itself could be necessary and sufficient in promoting underreplication. But, $>60 \%$ of transcripts located in fully replicated regions of the genome are also not expressed in the midgut, suggesting that underreplication is not essential for complete transcriptional shut off, and transcriptional shut off cannot induce underreplication. As an alternative approach to probe the relationship between underreplication and transcriptional shut off, we scanned our mRNA-seq datasets for transcriptionally silent regions of $\geq 100 \mathrm{~kb}$ to determine whether transcriptional shut off was sufficient to induce underreplication (Supplemental Table 5; Supplemental Fig. S5). Consistent with the finding that underreplicated regions in the salivary gland and midgut tissues are transciptionally silent, we identified 33 of 40 (89\%) salivary gland underreplicated sites and 19 of 21 (90\%) midgut underreplicated regions in transcriptionally silent windows. In contrast, only six of the 15 (40\%) fat body underreplicated sites were within transcriptionally silent windows. Not only did we identify transcriptionally silent underreplicated regions, but we also identified numerous fully replicated regions with no transcription in all three tissues (Supplemental Table 5; Supplemental Fig. S5). This indicates that transcriptional shut off is not sufficient to induce underreplication.

\section{Functional analysis of tissue-specific transcription}

Because we observed marked differences in transcript levels in underreplicated regions of the salivary gland and midgut tissues when compared with the fat body, it was important to analyze the expressed gene products in these tissues to verify the quality of our mRNA-seq data sets. Although microarray expression studies have been published for these tissues ( $\mathrm{Li}$ and White 2003; Jiang et al. 2005), our mRNA-seq experiments produced a comprehensive identification of expressed genes, with many more transcribed genes recognized than in previous studies. A total of 11,210 total transcripts were expressed in the fat body, midgut, and salivary gland tissues, collectively, with 4861 (43\%) common to all three tissues, and 8231, 8997, and 6426 transcripts expressed in the fat body, midgut, and salivary gland, respectively. Of these transcripts, 1503 (18\%) were specific to the fat body, while 1641 (18\%) and 483
(8\%) were specific to the midgut and salivary gland, respectively (Fig. 5).

Given the unique roles that these tissues perform in larval development, we predicted that tissue-specific transcripts would highlight the functions of these tissues in development. To test this hypothesis, we performed Gene Ontology (GO) analysis on transcripts expressed uniquely in each tissue (Huang et al. 2009). Fat body-specific transcripts were highly enriched in GO categories associated with the generation of energy, metabolism, and nutrient transport. This is consistent with the known role of the fat body in larval metabolism and its role as an organismal nutrient sensor (Colombani et al. 2003; Leopold and Perrimon 2007). Midgut-specific transcripts were enriched in GO categories such as larval or pupal organ development and morphogenesis, metamorphosis, and imaginal disc development. The latter categories likely reflect the developmental events as the larval midgut is degraded and the adult midgut rebuilt from imaginal islands in the midgut (Skaer 1993; Jiang et al. 2009; Mathur et al. 2010). Salivary gland-specific transcripts were enriched in GO processes such as puparial adhesion, molting cycle, and DNA replication, again consistent with tissue function (Supplemental Tables 3-5). Taken together, these results demonstrate that tissue-specific transcriptional profiling can reveal important biological insight into tissuespecific functions during development. Furthermore, the specificity of the GO terms revealed in our analysis verifies the purity of each tissue sample isolated for this analysis.

\section{Discussion}

We found that euchromatic, nonrepetitive, gene-encoding regions of multiple polytene tissues display common sites of underreplication. Importantly, we observed tissue-specific regions of underreplication and demonstrated that underreplication is dependent on SuUR in all tissues examined. Notably, there was little to no active transcription in underreplicated regions of the midgut, but transcription was readily detectable in underreplicated regions of the fat body. These results indicate that a developmental bypass of transcriptional shut off occurs in underreplicated regions of the fat body.

A myriad of studies have established a link between active transcription and replication timing (Hatton et al. 1988; Taljanidisz et al. 1989; Schubeler et al. 2002; MacAlpine et al. 2004; Jeon et al. 2005). For example, across multiple cell lines it was demonstrated that actively transcribed genes generally replicate early in $S$ phase. Additionally, immunoglobulin genes that are transcriptionally silent are replicated in the first half of $S$ phase, but are replicated even earlier in cell lines where those genes are expressed (Hatton et al. 1988). More recently, multiple genome-wide studies have

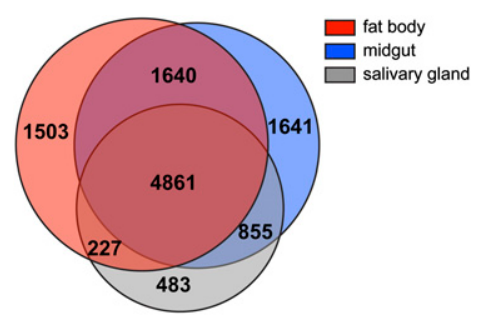

Figure 5. Tissue specificity of transcripts. Diagram illustrates the number of transcripts common to each tissue or the number of transcripts whose expression is shared between tissues. 
established that ORC localization is enriched at active promoters, and early origin usage is correlated with gene expression (Schubeler et al. 2002; MacAlpine et al. 2004; Jeon et al. 2005). Our finding that underreplicated regions in the midgut and salivary gland are generally transcriptionally silent supports the positive relationship between transcriptional activation and origin firing. It is significant, however, that transcription occurs in underreplication regions of the fat body, where replication must be silenced. Therefore, transcription is not sufficient to restore replication to these inefficiently replicated domains. In addition, transcriptional silencing cannot be sufficient to promote underreplication, because we observed transcriptionally inactive regions that were not underreplicated.

The tissue specificity of underreplication suggests that factors in differentiated cells are needed to control replication. Given that underreplication is SUUR dependent in all tissues examined, we propose that SUUR is a general replication factor, and that SUUR function is modulated in a tissue-specific manner. This could occur by affecting the activity of SUUR or its recruitment to chromatin or by indirectly affecting SUUR function through tissue-specific changes in chromatin structure. SUUR is associated with a repressive chromatin domain that covers $48 \%$ of the genome in Drosophila tissue culture and is generally transcriptionally silent and late replicating (Filion et al. 2010). How this domain is established and modulated during development is not understood.

In addition to the tissue specificity of underreplicated regions, we observed tissue-specific differences in the extent of underreplication. This provides insight into the mechanism by which underreplication is established. The degree of underreplication could parallel the number of endo cycles in a given tissue, with each cycle resulting in a higher degree of underreplication. This is not the case for the larval fat body and midgut given their similar ploidy levels but differences in underreplication. In the salivary gland underreplication begins from the first endocycles and appears constant throughout all endo cycles (N Sher, S Li, G Bell, T Eng, M Eaton, D MacAlpine, and TL Orr-Weaver, in prep.). In contrast, the difference in underreplication between the larval fat body and midgut, which have similar ploidy levels, indicates that there can be developmental tissue specificity governing in which endo cycle underreplication begins, whether underreplication is continuous throughout all endo cycles, and/or whether there is cell or strand specificity.

Despite the many domains of underreplication, we failed to find evidence of amplification, raising the question in Drosophila: Why is amplification observed only in ovarian follicle cells? The salivary gland is highly metabolically active, but because it is able to perform its function over a longer developmental time frame and has very high ploidy, amplification may not be necessary for increased gene expression. The fat body and midgut have lower ploidy levels relative to the salivary gland, but higher than the $16 \mathrm{C}$ follicle cells. Moreover, gene expression in these tissues also likely occurs over a longer developmental window, and this could negate a need for amplification. Another example of developmental gene amplification occurs in the sciarid flies, in which genes encoding cocoon proteins are amplified in the larval salivary glands (Glover et al. 1982; Wu et al. 1993; Santelli et al. 2004) In the case of the eggshell protein genes in the Drosophila follicle cells and the cocoon protein genes in the sciarid flies, it may be that when confronted with the developmental demand to express a limited set of genes at extremely high levels over a brief developmental window, increased copy number of a subset of genes above the overall ploidy of the genome has been selected.
By working with dissected and purified tissue, combined with the power of next-generation sequencing technologies, we were able to generate a high-quality expression profile of the larval fat body and midgut. Additionally, we were able to extend our analysis by utilizing an expression profile of the larval salivary gland to generate a three-tissue comparison at the same developmental time point. Tissue-specific transcriptional profiling has the potential to reveal gene networks that underlie the developmental and biological function of those tissues, which would have been missed by whole animal transcriptional profiling (Li and White 2003). Indeed, we identified a large number of transcripts that are specifically expressed in the larval fat body, midgut, or salivary gland tissues. Furthermore, the GO categories associated with these transcripts accurately represent many of the biological functions associated with these tissues, underscoring the quality of these comprehensive data sets.

In summary, by profiling dissected and purified tissues rather than whole animals, we have shown that changes in gene copy number can occur in a tissue-specific manner during development. Repressive chromatin marks and an absence of transcription are associated with late replication in diploid cell culture and underreplication in the salivary gland (MacAlpine et al. 2004). Given the marked differences in these two cell types, it might have been predicted that these regions would be underreplicated and blocked for transcription in all polytene cells. In contrast, our results clearly demonstrate that this is not the case. This raises the intriguing possibility that tissue-specific remodeling of chromatin occurs in order to generate a developmental plasticity with respect to replication.

\section{Methods}

\section{Comparative genomic hybridization}

Salivary glands, midguts, and fat bodies were dissected from either modENCODE OregonR (wild type) or SuUR third instar wandering larvae ( $\sim 50$ larvae/tissue). To eliminate contaminating signal from the larval gonads, which are attached to the larval fat body, male larvae were selected for dissection and the gonads were removed. DNA was isolated from tissues and embryos as described (Royzman et al. 1999) and labeled with the Invitrogen BioPrime Total for Agilent aCGH kit according to the manufacturer's protocol. Both experimental and embryonic control DNA were hybridized to tiling arrays containing probes every 250 or 125 bp spanning the entire Drosophila genome. The slides were hybridized and washed as recommended by Agilent and scanned using an Agilent microarray scanner. The resulting data was then LOESS normalized and $\log _{2}$ ratios were generated from the normalized data using the software package Ringo in R (Toedling et al. 2007). Biological replicates were performed for each tissue type. To identify regions of underreplication, we demanded at least a twofold level of underreplication in replicate aCGH experiments.

\section{Quantitative real-time PCR}

Genomic DNA for PCR was isolated from salivary glands, midguts, and fat bodies of third instar larvae as previously described. Quantitative real-time PCR was performed as described (Claycomb et al. 2002), except that PerfeCTa SYBR Green FastMix, ROX was used (Quanta Biosciences). Primers were designed using Applied Biosystems Primer Express software to fall near the middle of the underreplication troughs. All experimental PCR reactions were normalized to a fully replicated control interval within 93F2 to calculate the degree of underreplication.

\section{Genome Research}




\section{RNA-sequencing}

Total RNA was extracted from dissected and purified tissues $(\sim 50$ larvae/tissue) with TRIzol (Invitrogen) according to the manufacturer's protocol. The mRNA-seq library was prepared from $5 \mathrm{ug}$ of total RNA using the mRNA-seq Sample Preparation kit from Illumina as specified. mRNA-Seq reads were aligned to BDGP Release 5/DM3 using ELAND, using the first 25 bases of a read as a seed. Each matched seed was then extended up to 36 bases and scored to break any ties between multimatches. For mRNA expression counts, unique reads in the genome that landed within any known exons were counted. The counts were normalized by the mRNA length to get the final reads per kilobase per million (RPKM) values.

\section{Quantification of ploidy}

Larval salivary glands, midguts, and fat bodies were fixed with $4 \%$ formaldehyde and stained with $50 \mathrm{ng} / \mathrm{mL}$ DAPI for $1 \mathrm{~h}$ at room temperature. DAPI intensities of the experimental nuclei were measured and compared with the intensities of the $2 \mathrm{C}$ larval antennal disc nuclei to determine ploidy level. At least 40 nuclei from two biological replicates were used per tissue type for quantification.

\section{Acknowledgments}

We thank Sumeet Gupta in the Whitehead Institute's Genome Core Facility for the alignment and sequence counting of the Illumina mRNA-sequencing data. We thank Inma Barrasa and George Bell, both in the Whitehead Institute's Bioinformatics and Research Computing (BaRC) department, for assistance with the window analysis and invaluable bioinformatics advice, respectively. Iva Kronja, Noa Sher, and Steve Bell provided helpful comments on the manuscript. J.N. is an HHMI Fellow of the Damon Runyon Cancer Research Foundation. This research was initiated with support from the Mathers Charitable Foundation and NIH grant HG004279 as part of the modENCODE project. This work also was funded by NIH grant GM57960 to T.O.-W. who is an American Cancer Society Research Professor.

\section{References}

Belyaeva ES, Zhimulev IF, Volkova EI, Alekseyenko AA, Moshkin YM, Koryakov DE. 1998. Su(UR)ES: A gene suppressing DNA underreplication in intercalary and pericentric heterochromatin of Drosophila melanogaster polytene chromosomes. Proc Natl Acad Sci 95: 7532 7537.

Butterworth FM, Forrest EC. 1984. Ultrastructure of the preparative phase of cell death in the larval fat body of Drosophila melanogaster. Tissue Cell 16: 237-250.

Butterworth FM, Rasch EM. 1986. Adipose tissue of Drosophila melanogaster: VII. Distribution of nuclear DNA amounts along the anterior-posterior axis in the larval fat body. J Exp Zool 239: 77-85.

Claycomb JM, MacAlpine DM, Evans JG, Bell SP, Orr-Weaver TL. 2002. Visualization of replication initiation and elongation in Drosophila. JCell Biol 159: 225-236.

Claycomb JM, Benasutti M, Bosco G, Fenger DD, Orr-Weaver TL. 2004. Gene amplification as a developmental strategy: Isolation of two developmental amplicons in Drosophila. Dev Cell 6: 145-155.

Colombani J, Raisin S, Pantalacci S, Radimerski T, Montagne J, Leopold P. 2003. A nutrient sensor mechanism controls Drosophila growth. Cell 114: $739-749$.

Edgar BA, Orr-Weaver TL. 2001. Endoreplication cell cycles: More for less. Cell 105: 297-306.

Eisen MB, Spellman PT, Brown PO, Botstein D. 1998. Cluster analysis and display of genome-wide expression patterns. Proc Natl Acad Sci 95: 14863-14868.

Filion GJ, van Bemmel JG, Braunschweig U, Talhout W, Kind J, Ward LD, Brugman W, de Castro IJ, Kirkhoven RM, Bussemaker HJ, et al. 2010. Systematic protein location mapping reveals five principal chromatin types in Drosophila cells. Cell 143: 212-224.
Glover DM, Zaha A, Stocker AJ, Santelli RV, Pueyo MT, De Toledo SM, Lara FJ. 1982. Gene amplification in Rhynchosciara salivary gland chromosomes. Proc Natl Acad Sci 79: 2947-2951.

Hatton KS, Dhar V, Brown EH, Iqbal MA, Stuart S, Diadmo VT, Schildkraut CL. 1988. Replication program of active and inactive multigene families in mammalian cells. Mol Cell Biol 8: 2149-2158.

Hochstrasser M. 1987. Chromosome structure in four wild-type polytene tissues of Drosophila melanogaster. The 87A and 87C heat shock loci are induced unequally in the midgut in a manner dependent on growth temperature. Chromosoma 95: 197-208.

Hochstrasser M, Sedat JW. 1987. Three-dimensional organization of Drosophila melanogaster interphase nuclei. I. Tissue-specific aspects of polytene nuclear architecture. J Cell Biol 104: 1455-1470.

Huang DW, Sherman BT, Lempicki RA. 2009 Systematic and integrative analysis of large gene lists using DAVID bioinformatics resources. Nat Protoc 4: 44-57.

Jeon Y, Bekiranov S, Karnani N, Kapranov P, Ghosh S, MacAlpine D, Lee C, Hwang DS, Gingeras TR, Dutta A. 2005. Temporal profile of replication of human chromosomes. Proc Natl Acad Sci 102: 6419-6424.

Jiang H and Edgar BA. 2009. EGFR signaling regulates the proliferation of Drosophila adult midgut progenitors. Development 136: 483-493.

Jiang Z, Wu XL, Michal JJ, McNamara JP. 2005. Pattern profiling and mapping of the fat body transcriptome in Drosophila melanogaster. Obes Res 13: 1898-1904.

Lee HO, Davidson JM, Duronio RJ. 2009. Endoreplication: Polyploidy with purpose. Genes Dev 23: 2461-2477.

Leopold P, Perrimon N. 2007. Drosophila and the genetics of the internal milieu. Nature 450: $186-188$.

Li TR, White KP. 2003. Tissue-specific gene expression and ecdysoneregulated genomic networks in Drosophila. Dev Cell 5: 59-72.

Lilly MA, Duronio RJ. 2005. New insights into cell cycle control from the Drosophila endocycle. Oncogene 24: 2765-2775.

MacAlpine DM, Rodríguez HK, Bell SP. 2004. Coordination of replication and transcription along a Drosophila chromosome. Genes Dev 18: 3094 3105.

Marchetti M, Fanti L, Berloco M, Pimpinelli S. 2003. Differential expression of the Drosophila BX-C in polytene chromosomes in cells of larval fat bodies: A cytological approach to identifying in vivo targets of the homeotic Ubx, Abd-A and Abd-B proteins. Development 130: 3683-3689.

Mathur D, Bost A, Driver I, Ohlstein B. 2010. A transient niche regulates the specification of Drosophila intestinal stem cells. Science 327: 210-213.

Pindyurin AV, Moorman C, de Wit E, Belyakin SN, Belyaeva ES, Christophides GK, Kafatos FC, van Steensel B, Zhimulev IF. 2007. SUUR joins separate subsets of PcG, HP1 and B-type lamin targets in Drosophila. J Cell Sci 120: 2344-2351.

Rodman TC. 1967. DNA replication in salivary gland nuclei of Drosophila melanogaster at successive larval and prepupal stages. Genetics 55: 375386.

Royzman I, Austin RJ, Bosco G, Bell SP, Orr-Weaver TL. 1999. ORC localization in Drosophila follicle cells and the effects of mutations in dE2F and dDP. Genes Dev 13: 827-840.

Santelli RV, Siviero F, Machado-Santelli GM, Lara FJ, Stocker AJ. 2004 Molecular characterization of the B-2 DNA puff gene of Rhynchosciara americana. Chromosoma 113: 167-176.

Schubeler D, Scalzo D, Kooperberg C, van Steensel B, Delrow J, Groudine M. 2002. Genome-wide DNA replication profile for Drosophila melanogaster: A link between transcription and replication timing. Nat Genet 32: 438442 .

Skaer H. 1993. The alimentary canal. In The development of Drosophila melanogaster (ed. M Bate, A Martinez Arias), pp. 941-1012. Cold Spring Harbor Laboratory Press, Cold Spring Harbor, NY.

Smith AV, Orr-Weaver TL. 1991. The regulation of the cell cycle during Drosophila embryogenesis: The transition to polyteny. Development 112: 997-1008.

Spradling A, Orr-Weaver T. 1987. Regulation of DNA replication during Drosophila development. Annu Rev Genet 21: 373-403.

Taljanidisz J, Popowski J, Sarkar N. 1989. Temporal order of gene replication in Chinese hamster ovary cells. Mol Cell Biol 9: 2881-2889.

Toedling J, Skylar O, Krueger T, Fischer JJ, Sperling S, Huber W. 2007. Ringo-an R/Bioconductor package for analyzing ChIP-chip readouts. BMC Bioinformatics 8: 221. doi: 10.1186/1471-2105-8-221.

Wu N, Liang C, DiBartolomeis SM, Smith HS, Gerbi SA. 1993. Developmental progression of DNA puffs in Sciara coprophila: Amplification and transcription. Dev Biol 160: 73-84.

Zimmet J, Ravid K. 2000. Polyploidy: Occurrence in nature, mechanisms, and significance for the megakaryocyte-platelet system. Exp Hematol 28: $3-16$

Received August 30, 2010; accepted in revised form October 26, 2010. 


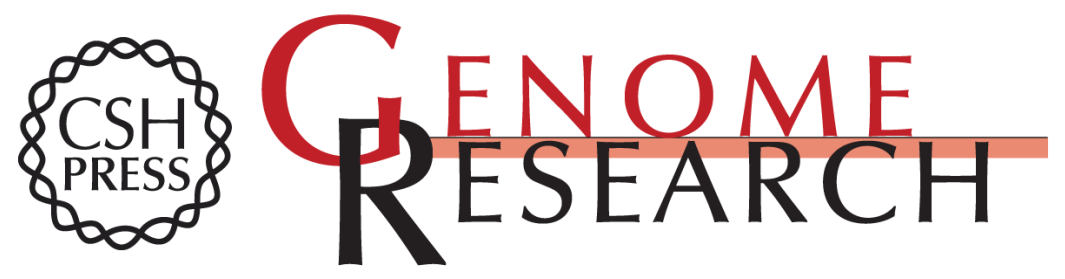

\section{Developmental control of the DNA replication and transcription programs}

Jared Nordman, Sharon Li, Thomas Eng, et al.

Genome Res. 2011 21: 175-181 originally published online December 22, 2010

Access the most recent version at doi:10.1101/gr.114611.110

Supplemental http://genome.cshlp.org/content/suppl/2010/11/02/gr.114611.110.DC1 Material

\section{Affordable, Accurate Sequencing.}


Related Content

References This article cites 35 articles, 16 of which can be accessed free at: http://genome.cshlp.org/content/21/2/175.full.html\#ref-list-1

Articles cited in:

http://genome.cshlp.org/content/21/2/175.full.html\#related-urls

Open Access Freely available online through the Genome Research Open Access option.

License Freely available online through the Genome Research Open Access option.

Email Alerting Receive free email alerts when new articles cite this article - sign up in the box at the Service top right corner of the article or click here.

\section{Affordable, Accurate} Sequencing.

To subscribe to Genome Research go to: https://genome.cshlp.org/subscriptions 